\title{
IMPROVING THE QUALITY OF DRIVE SYSTEM USING ADAPTIVE FUZZY CONTROLLER METHOD
}

\section{NGUYEN THUY DUNG, NGUYEN THI PHUONG THANH \& DINH TRAN NGOC HUY}

Research Scholar, Thai Nguyen University of Information and Communication Technology, Vietnam Research Scholar, Thai Nguyen University of Information and Communication Technology, Vietnam

Research Scholar, Banking University HCMC, Ho Chi Minh city, Vietnam-International University of Japan, Japan

\begin{abstract}
This article studies gear transmission. This is one of the most common actuators in a range of machines. For problems requiring high accuracy with the assumption that it is impossible to accurately measure friction torque, elastic deformation, torque on the driveshaft and the gap between gears, one must use additional The same mechanical solutions are electronic and electronic controllers so that it is easy to set up adjustment control methods to compensate for the number of deviations that mechanical devices cannot solve. The paper presents a new control method to improve the quality of gear transmission by a fuzzy adaptive controller. Simulation results on Matlab-Simulink software have shown the effectiveness of the proposed method.

KEYWORDS: Fuzzy Logic Controller; Fuzzy Adaptive Controller, Gear Systems; the Method for Control Gear System; PID Controller
\end{abstract}

Received: Jun 09, 2020; Accepted: Jun 29, 2020; Published: Aug 07, 2020; Paper Id.: IJMPERDJUN2020694

\section{INTRODUCTION}

The gap-free drive system is a non-linear transmission system which is widely used in practice such as gear transmission, belt drive, chain drive, etc. In the gear system, the transmission is carried out. Thanks to the matching of the gears on the gear or the gear bar. Gear drives are used in many different types of machines and mechanisms to transfer rotational motion from one axis to another and to convert rotary motion into linear motion and vice versa. Gear transmission is one of the transmission systems with gaps with outstanding advantages: Ensuring relative transmission accuracy due to less slip, fixed gear ratio, high efficiency $0.96 \div 0,98$, even 0.99 for a pair of gear.

However, when assembling and operating the gear transmission system more or less still generates dynamic loads, causing vibration shocks that cause concentrated stress on the working part of the teeth that can cause fractures or chipping. Noise, and generate heat, errors. Therefore study and describe the random effects of gear structure (representing the gaped transmission) on the quality of the electric drive system, At the same time, we propose methods to use the adaptive fuzzy controller to overcome these effects, on the other hand, the results can be used as a basis for further research to find new solutions. Based on applying modern control methods to improve the quality of the power train have gears.

\section{METHODS}

Based on evaluation, comparison between classical control method and fuzzy adaptive control to control design, 
the random effect of gear structure on the quality of the electric drive system with the results of theoretical and simulation studies will show the control effect when using the fuzzy adaptive controller to Improve the quality of gear transmission. Building a mathematical model for an independent magnetic DC motor to control the engine speed in the drive system, and then putting the nonlinear equation systems built into the drive system and performing simulation. on MATLAB software

\section{MATHEMATICAL DESCRIPTION OF GEAR TRAIN}

Figure 1 shows Based on the New York law of motion, consider the case where only one pair of serial deformations are in contact with each other at the center of the P-joint in the actual articulation segment of the gear pair and call $\omega 1 ; \omega 2$ is the angular velocity and angular acceleration of gears 1 and 2 . We have established the dynamic equation of a pair of gears as follows:

$$
\left\{\begin{array}{l}
\mathrm{J}_{1}^{\prime} \dot{\omega}_{1}+\mathrm{b}_{1} \omega_{1}+\mathrm{M}_{\mathrm{dh} 1}=\mathrm{M}_{\mathrm{d}} \\
\mathrm{J}_{2} \dot{\omega}_{2}+\mathrm{b}_{2} \omega_{2}-\mathrm{M}_{\mathrm{dh} 2}=-\mathrm{M}_{\mathrm{tai}}
\end{array}\right.
$$

Inside:

$$
\mathrm{J}_{1}^{\prime}=\mathrm{J}_{\mathrm{d}}+\mathrm{J}_{1}
$$

Mdh1, Mdh2: elastic moment

Md: motor torque

Mtai: depending on the type of load, for example Mtai $=$ Mtai $(\omega 2, \omega 1, t)$

Mms: Assuming that the drives are lubricated with oil, the friction force is proportional to the speed. We have the following equation:

$$
\left\{\begin{array}{l}
\mathrm{J}_{1}^{\prime} \dot{\omega}_{1}+\mathrm{b}_{1} \omega_{1}+\mathrm{M}_{\mathrm{dh} 1}=\mathrm{M}_{\mathrm{d}} \\
\mathrm{J}_{2} \dot{\omega}_{2}+\mathrm{b}_{2} \omega_{2}-\mathrm{M}_{\mathrm{dh} 2}=-\mathrm{M}_{\mathrm{c}}
\end{array}\right.
$$

If friction losses are omitted, the transmission power of the gear pairs is constant, which means:

$$
' \operatorname{Mdh} 1 . \omega 1=\operatorname{Mdh} 2 . \omega 2 \rightarrow M_{\mathrm{dh} 1}=\mathrm{M}_{\mathrm{dh} 2} \frac{\omega_{2}}{\omega_{1}}
$$

We have:

$$
\mathrm{M}_{\mathrm{dh} 1}=\mathrm{M}_{\mathrm{dh} 2}\left[-\frac{\mathrm{r}_{10}}{\mathrm{r}_{20}}+\frac{\delta_{1}}{\mathrm{r}_{20}}-\frac{\mathrm{r}_{10}}{\mathrm{r}_{20}^{2}} \cdot \delta_{2}\right]
$$

Remove Mdh1 and Mdh2 from equation (3) by (1) we have

$$
\mathrm{J}_{1}^{\prime} \dot{\omega}_{1}+\mathrm{b}_{1} \omega_{1}+\left(\mathrm{J}_{2} \dot{\omega}_{2}+\mathrm{b}_{2} \omega_{2}+\mathrm{M}_{\mathrm{c}}\right)\left[-\frac{\mathrm{r}_{10}}{\mathrm{r}_{20}}+\frac{\delta_{1}}{\mathrm{r}_{20}}-\frac{\mathrm{r}_{10}}{\mathrm{r}_{20}^{2}} \delta_{2}\right]=\mathrm{M}_{\mathrm{d}}
$$




$$
\begin{aligned}
& \mathrm{J}_{2}\left(-\frac{\mathrm{r}_{10}}{\mathrm{r}_{20}}+\frac{\delta_{1}}{\mathrm{r}_{20}}-\frac{\mathrm{r}_{10}}{\mathrm{r}_{20}^{2}} \delta_{2}\right) \dot{\omega}_{2}+\mathrm{b}_{2}\left(-\frac{\mathrm{r}_{10}}{\mathrm{r}_{20}}+\frac{\delta_{1}}{\mathrm{r}_{20}}-\frac{\mathrm{r}_{10}}{\mathrm{r}_{20}^{2}} \delta_{2}\right) \omega_{2} \\
& +\left(-\frac{\mathrm{r}_{10}}{\mathrm{r}_{20}}+\frac{\delta_{1}}{\mathrm{r}_{20}}-\frac{\mathrm{r}_{10}}{\mathrm{r}_{20}^{2}} \delta_{2}\right) \mathrm{M}_{\mathrm{c}}=\mathrm{M}_{\mathrm{d}}-\mathrm{J}_{1}^{\prime} \dot{\omega}_{1}-\mathrm{b}_{1} \omega_{1}
\end{aligned}
$$

Equations (1) and (3) are equations of speed equilibrium and torque equations of gear structure, taking into account the random gap differences and the influence of elasticity. Gears of gears, shafts, and mention of friction between bearings. These equations are used to investigate and evaluate the impact of gear mechanisms on the quality of their drive systems.
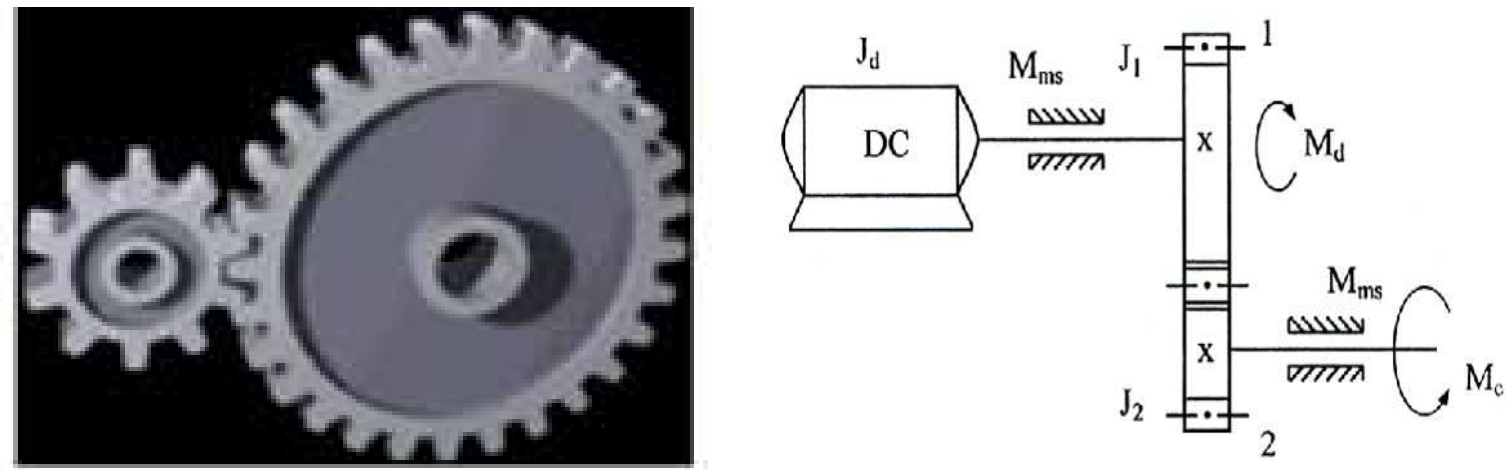

Figure 1: Physical Structure of the Drive System through a Pair of Gears.

\section{THE EFFECTS OF GEAR CAKE TO THE QUALITY OF THE TRAFFIC}

\subsection{Block Diagram of Gear Transmission}

Figure 2 shows in which the electric motor is fed from the grid through the controller, the motor shaft is connected to the active gear and the motion is transferred to the production machine via a passive gear (or an intermediate gear). Gear drives are used in many different types of machines and mechanisms to transfer rotational motion from one axis to another or to turn a rotary motion into a linear motion and vice versa. Gear drives are important components in cars, internal combustion engines, machine tools, agricultural machines, cranes, and many other types of equipment.

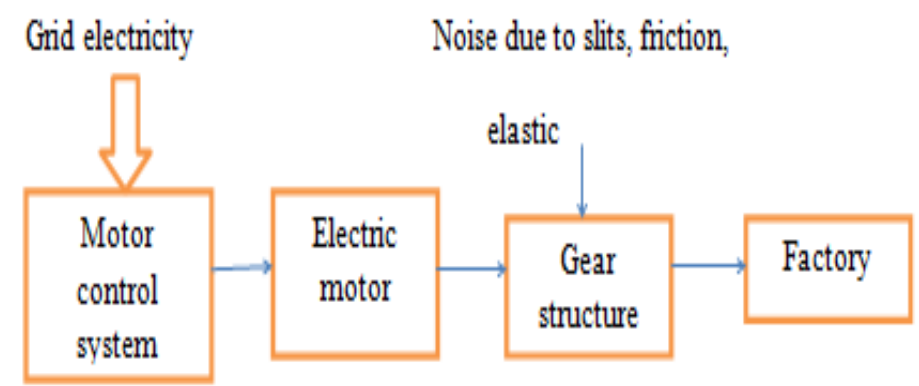

Figure 2: Block Diagram of Gear Transmission

\subsection{Simulate Gear Operation}

Considering gear structure includes 2 straight gears, cylindrical teeth. The equation describing the speed relation of the active gear shaft and passive gear shaft is: $\omega_{2}=\left[-\frac{r_{10}}{r_{20}}+\frac{\delta_{1}}{r_{20}}-\frac{r_{10}}{r_{20}^{2}} \delta_{2}\right] \omega_{1}$ 
Inside:

$\mathrm{r} 10, \mathrm{r} 20$ are the design radius of gear 1 and pin 2

$\mathrm{r} 1, \mathrm{r} 2$ are their true radius (also called manufacturing radius)

Let $\delta 1, \delta 2$ be the deviation between the design radius and the actual radius we have:

$$
\begin{aligned}
& r 1=r 10-\delta 2 \\
& r 2=r 20-\delta 2
\end{aligned}
$$

From the relation between the speeds of the active and passive axes, we have a simulation diagram and the immediate relationship of the speed of the two passive gears when considering the gap due to manufacturing errors.

Figure 4 shows the simulation results in Figure 3 show that due to the impact of gap, elasticity, and friction, the passive shaft speed is oscillated, resulting in the instantaneous gear ratio of the ever-changing pair of gears, this change is calculated Random depends on the speed of the system.

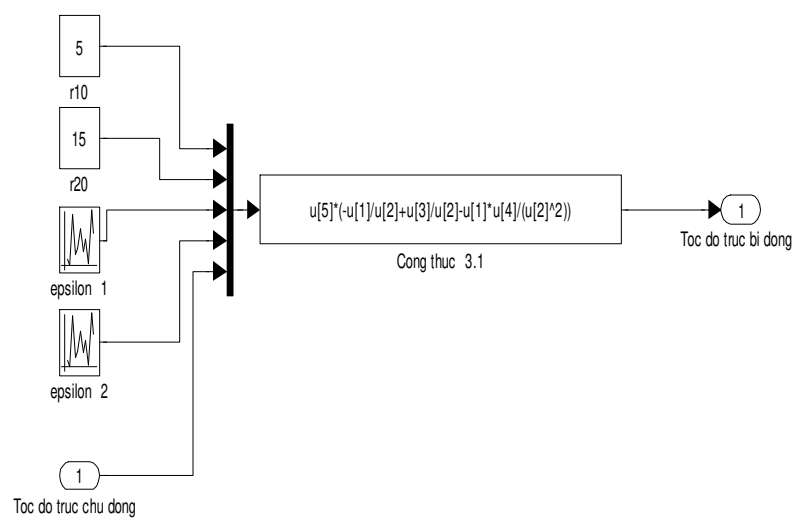

Figure 3: Diagram of Gear Transmission System.

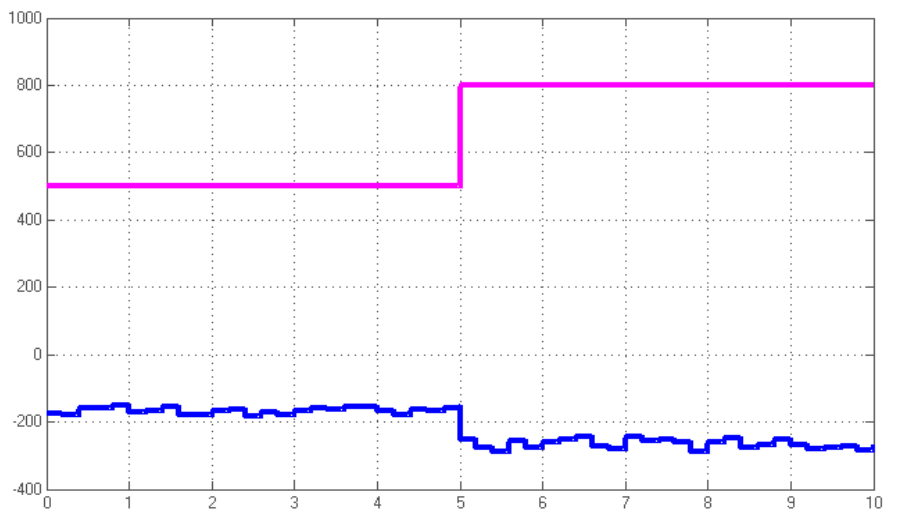

Figure 4: Speed Characteristics of Active and Passive Gears.

\subsection{Simulate the Relationship between the Torques in the Gear System}

We have the system of dynamic equations of pair of gears when mentioning the gap, elasticity, and friction:

$$
\mathrm{j}_{2}\left(-\frac{\mathrm{r}_{10}}{\mathrm{r}_{20}}+\frac{\delta_{1}}{\mathrm{r}_{20}}-\frac{\mathrm{r}_{10}}{\mathrm{r}_{20}^{2}} \delta_{2}\right) \dot{\omega}_{2}+\mathrm{b}_{2}\left(-\frac{\mathrm{r}_{10}}{\mathrm{r}_{20}}+\frac{\delta_{1}}{\mathrm{r}_{20}}-\frac{\mathrm{r}_{10}}{\mathrm{r}_{20}^{2}} \delta_{2}\right) \omega_{2}+\left(-\frac{\mathrm{r}_{10}}{\mathrm{r}_{20}}+\frac{\delta_{1}}{\mathrm{r}_{20}}-\frac{\mathrm{r}_{10}}{\mathrm{r}_{20}^{2}} \delta_{2}\right) \mathrm{M}_{\mathrm{c}}=\mathrm{M}_{\mathrm{dc}}-\overline{\mathrm{J}}_{1} \dot{\omega}_{1}-\mathrm{b}_{1} \omega_{1}
$$




$$
\begin{aligned}
& {\left[\bar{J}_{1}+\mathrm{J}_{2}\left(-\frac{\mathrm{r}_{10}}{\mathrm{r}_{20}}+\frac{\delta_{1}}{\mathrm{r}_{20}}-\frac{\mathrm{r}_{10}}{\mathrm{r}_{20}^{2}} \delta_{2}\right)^{2}\right] \dot{\omega}_{2}+\left[\mathrm{b}_{1}+\mathrm{b}_{2}\left(-\frac{\mathrm{r}_{10}}{\mathrm{r}_{20}}+\frac{\delta_{1}}{\mathrm{r}_{20}}-\frac{\mathrm{r}_{10}}{\mathrm{r}_{20}^{2}} \delta_{2}\right)^{2}\right] \omega_{2}+\left(-\frac{\mathrm{r}_{10}}{\mathrm{r}_{20}}+\frac{\delta_{1}}{\mathrm{r}_{20}}-\frac{\mathrm{r}_{10}}{\mathrm{r}_{20}^{2}} \delta_{2}\right)^{2} \mathrm{M}_{\mathrm{c}}} \\
& =\left(-\frac{\mathrm{r}_{10}}{\mathrm{r}_{20}}+\frac{\delta_{1}}{\mathrm{r}_{20}}-\frac{\mathrm{r}_{10}}{\mathrm{r}_{20}^{2}} \delta_{2}\right) \mathrm{M}_{\mathrm{dc}}
\end{aligned}
$$

From (5) or (6), we simulate the relationship between the active shaft torque Mdc and the passive shaft torque Mc including gap, friction, and elasticity. Figure 5 below is a diagram of the dynamics of gear pairs

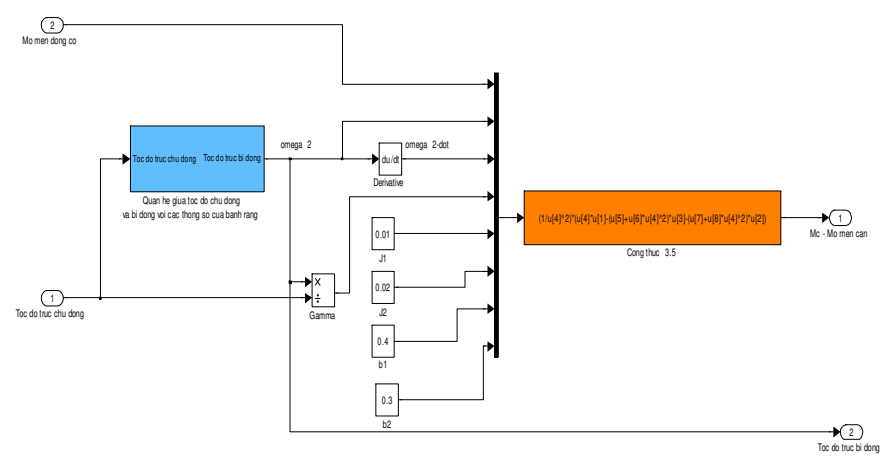

Figure 5: Diagram Simulating the Torque Relationship of Gear Pairs.

\section{DESIGNING PERIODIC PID FOR TRAFFIC THROUGH CARE}

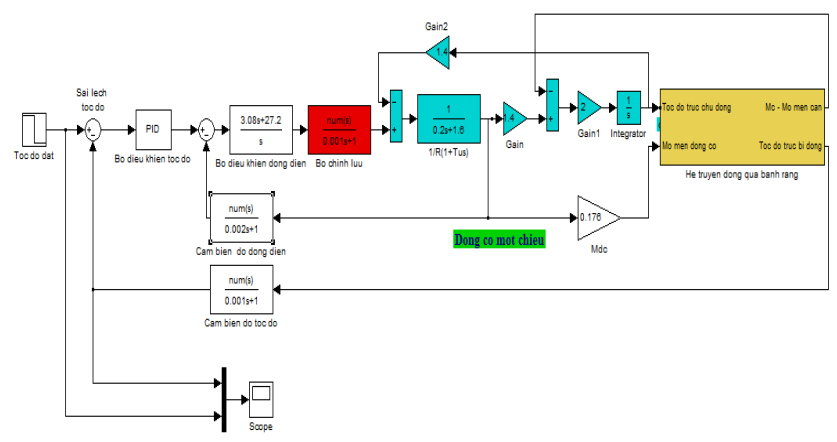

Figure 6: Diagram of a Gear Transmission System Using Classic PID.

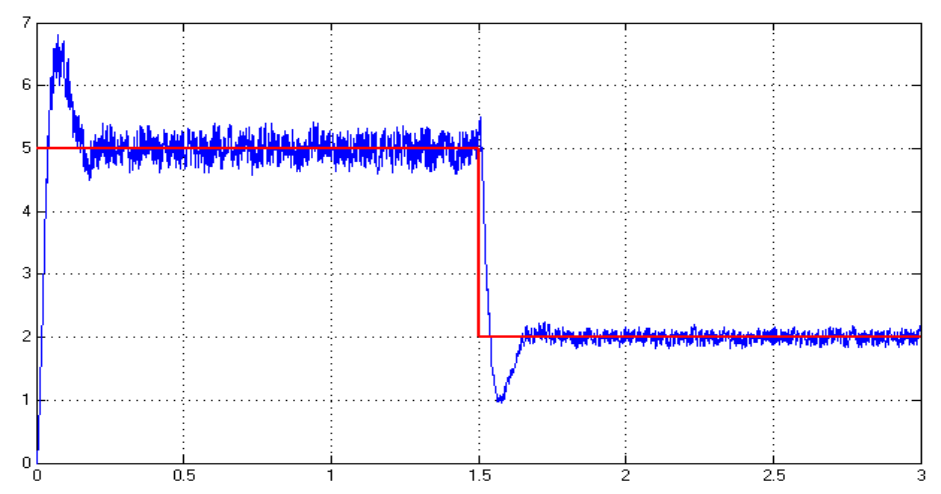

Figure 7: Transient Characteristic of Gear Transmission When Using Classic PID. 


\subsection{Fuzzy Adaptive Controller Structure}

With the characteristics of the gear transmission system, it is a nonlinear system with variable parameters and disadvantages, which are always under the impact of slits, elasticity, and friction. To control the system, we know there are many ways to overcome the fluctuations caused by gear structure, can choose PID controllers, modern controllers such as fuzzy, hybrid, and fuzzy controllers. Comfort... Each control method gives a certain efficiency and quality. The classic PID controllers are simple, easy to implement, but not suitable for the system, we have seen through the characteristics of the drive system. In which the controller follows the rule of differential proportions, the differential rule is kept constant and the ratio rule is a nonlinear controller consisting of a basic fuzzy controller whose output amplification coefficient is changed. According to the law: $\frac{\mathrm{dK}}{\mathrm{dt}}=2,5 \cdot \mathrm{e}^{2} \mathrm{k}$

The model has the form: $\mathrm{W}_{\mathrm{M}}=\frac{1}{0.1 \mathrm{~s}+1}$

The fuzzy controller has a function of input, output and I / O relation shown in the following figure:

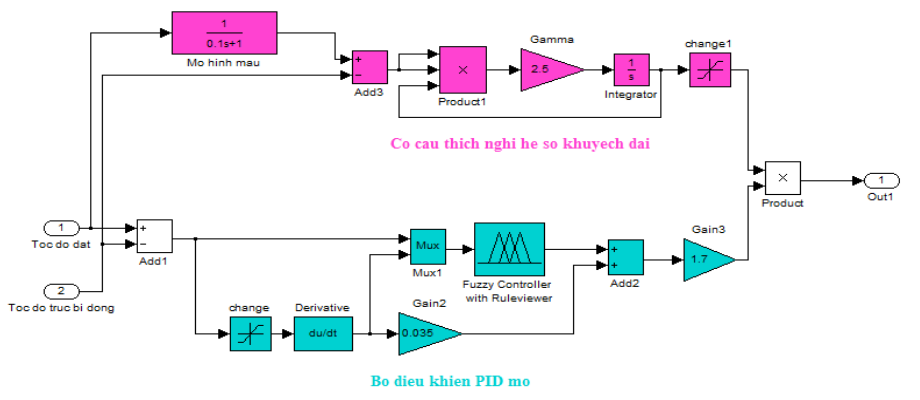

Figure 8: A) Structure of the Control System

B) Controller Structure and Adaptive Device.

\subsection{Simulation Results}

After the design of the fuzzy controller, connected to the object we have a simulation diagram as shown in Figure 11 and the simulation results are shown in Figure 12 and Figure 13.

Where Figure 12 is the dynamic characteristic line when using the adaptive fuzzy controller; Figure 13 shows the dynamic characteristics comparison results when using the classic PID controller and when using the fuzzy controller.
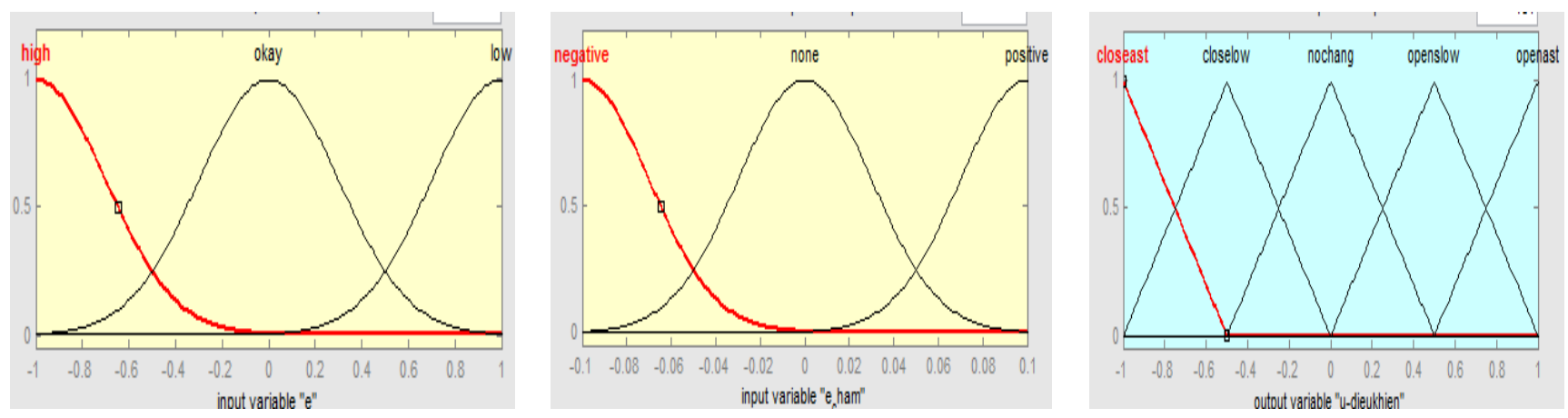

Figure 9: Interconnection Function Input and Output of Fuzzy Controller. 


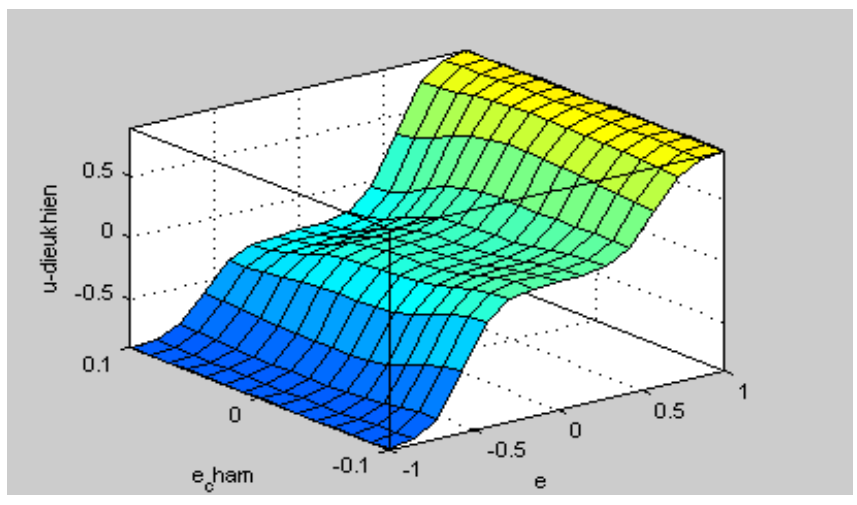

Figure 10: The In-Out Relationship of the Fuzzy Controller.

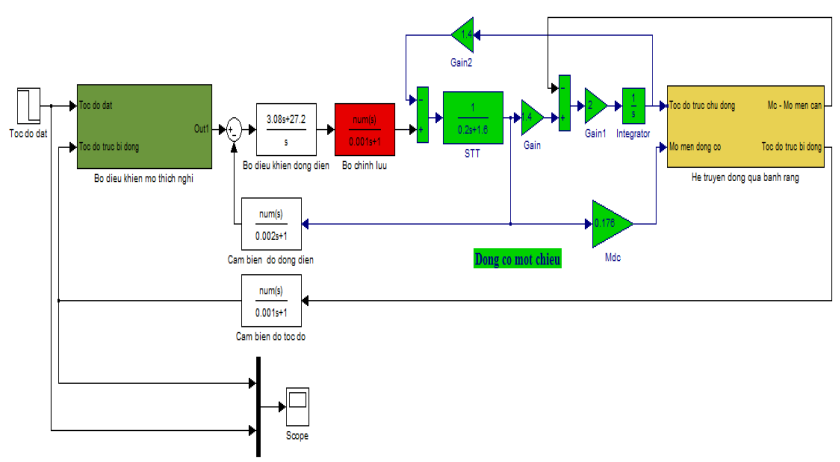

Figure 11: Diagram of Gear Transmission System When Using Adaptive Fuzzy Control.

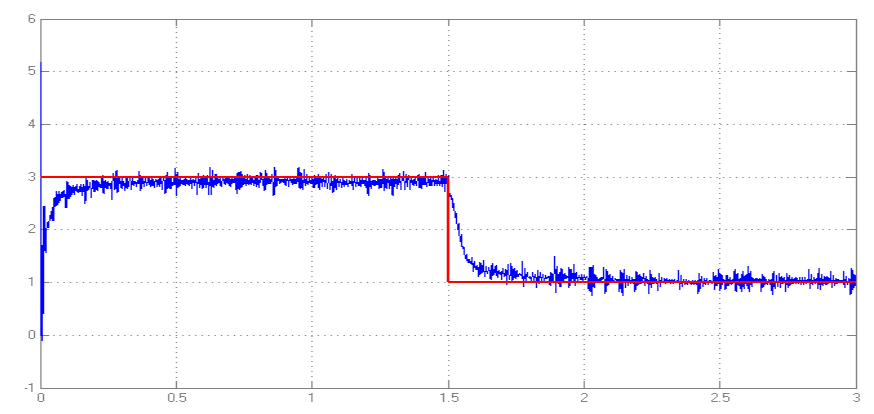

Figure 12: Transient Characteristic of Gear Transmission When Using Adaptive Dimming Control.I

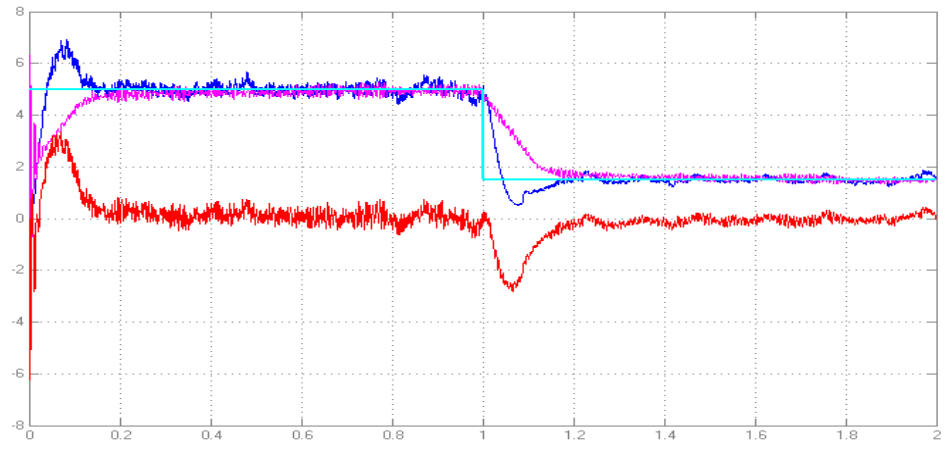

Figure 13: Speed Characteristics of Gear Transmission When Using Classic PID and When Using Adaptive Fuzzy Control. 


\section{CONCLUSIONS}

The research paper on a fuzzy controller with relatively complete properties such as strong nonlinearity, high anti-jamming ability, large band parameters and large delay time makes it very suitable for nonlinear systems to respond. Requested application in automatic control, besides, the fuzzy controllers allow us to repeat the properties of the classical controllers. The design of fuzzy controllers is also very diverse, by organizing control rules and selecting fuzzy sets for language variables that allow people to design different fuzzy controllers. The amount of work to be done when designing a fuzzy controller does not depend on the characteristics of the object. From the simulation results show that with the classic PID controller, the transient time, amplitude, vibration, impact of the passive axis speed increase; when the adaptive fuzzy controller has been replaced, the adaptive fuzzy controller has overcome the above problems, the dynamic quality increases markedly, the transient time decreases, the working process of the system is stable. Specified

\section{REFERENCES}

1. George Ellis, "Cures for Mechanical Resonance in Industrial Servo Systems", A Danaher Motion Company, USA.

2. "Mechanical Resonance", PT Design Magazine, 1999.

3. Le Thi Thu Ha; "Some solutions to improve the quality of transmission systems with gaps based on fuzzy systems and neural networks" Doctoral thesis on engineering (2013).

4. $\quad$ Nguyen Phung Quang: "Matlab \& Simulink", Science and Technology Publishing House, Hanoi, 2006.

5. Nguyen Doan Phuoc (2002), Theory of linear control, Workshop of University of Finance - Hanoi University of Science and Technology.

6. Nguyen Doan Phuoc \& Phan Xuan Minh \& Han Thanh Trung (2003), Theory of nonlinear control, Science and Technology Publishing House.

7. Phan Xuan Minh \& Nguyen Doan Phuoc (1999), Fuzzy control theory, Science and Technology Publishing House. English

8. Akira Chiba, Tadashi Fukao, Osamu Ichikawa, Masahide Oshima, asatsugu Takemoto, and David G. Dorrell, "Magnetic Bearings and Bearingless Drives", Newnes, 2005.

9. Chen, K.-Y. et al., A self-tuning fuzzy PID-type controller design for unbalance compensation in an active magnetic bearing, Expert Systems with Applications (2009), DOI:10.1016/j.eswa.2008.10.055.

10. Lu et al., Linear parameter-varying techniques for control of a magnetic bearing system, Control Engineering Practice 16 (2008) 1161-1172.

11. Parmar, Jigar K., and Sunny K. Darji \& Gajendra R. Patel. "Fuzzy Based MPPT Controller of Wind Energy Conversion System using PMSG." International Journal of Electrical and Electronics Engineering (IJEEE) 7.3 (2018): 1730.

12. Madhusudhanarao, G., V. Anwesha Kumar, And Bv Sankar Ram. "Damping Control Of Distributed Power Flow Controller For Improving The Transient Stability Using Fuzzy Logic Controller." International Journal Of Electronics, Communication \& Instrumentation Engineering Research And Development (Ijecierd) 6.5 (2016):18.

13. Kavitha, M., A. Sreekanth Reddy, And D. Mohan Reddy. "Power Quality Improvement Using Fuzzy Logic Controller Based Cmli And Fact Devices For Modern Power Systems." International Journal Of Electrical And Electronics Engineering Research (Ijeeer) 4.2 (2014):211222.

14. Kispotta, Anshu Mala. "Pid Control Strategy In Networked Control System." International Journal Of Computer Science And Engineering (Ijcse) 3.3 (2014):6782. 